\title{
Outcome of paediatric intensive care survivors
}

\author{
Hendrika Knoester • Martha A. Grootenhuis • \\ Albert P. Bos
}

Received: 26 April 2007 / Accepted: 10 July 2007 / Published online: 7 September 2007

(C) Springer-Verlag 2007

\begin{abstract}
The development of paediatric intensive care has contributed to the improved survival of critically ill children. Physical and psychological sequelae and consequences for quality of life (QoL) in survivors might be significant, as has been determined in adult intensive care unit (ICU) survivors. Awareness of sequelae due to the original illness and its treatment may result in changes in treatment and support during and after the acute phase. To determine the current knowledge on physical and psychological sequelae and the quality of life in survivors of paediatric intensive care, we undertook a computerised comprehensive search of online databases for studies reporting sequelae in survivors of paediatric intensive care. Studies reporting sequelae in paediatric survivors of cardiothoracic surgery and trauma were excluded, as were studies reporting only mortality. All other studies reporting aspects of physical and psychological sequelae were analysed. Twenty-seven studies consisting of 3,444 survivors met the selection criteria. Distinct physical and psychological sequelae in patients have been determined and seemed to interfere with quality of life. Psychological sequelae in parents seem to be common. Small numbers, methodological limitations and quantitative and qualitative heterogeneity hamper the interpretation of data. We
\end{abstract}

\footnotetext{
H. Knoester $(\bowtie) \cdot$ A. P. Bos

Paediatric Intensive Care Unit, Emma Children's Hospital,

Academic Medical Centre,

Meibergdreef 9,

1105 AZ Amsterdam, The Netherlands

e-mail: h.knoester@amc.uva.nl

M. A. Grootenhuis

Psychosocial Department, Emma Children's Hospital,

Academic Medical Centre,

Amsterdam, The Netherlands
}

conclude that paediatric intensive care survivors and their parents have physical and psychological sequelae affecting quality of life. Further well-designed prospective studies evaluating sequelae of the original illness and its treatment are warranted.

Keywords Paediatric intensive care unit .

Outcome assessment (health care) - Quality of life .

Post-traumatic stress disorder $\cdot$ Health status

\begin{tabular}{|c|c|}
\hline \multicolumn{2}{|c|}{ Abbreviations } \\
\hline ARDS & adult respiratory distress syndrome \\
\hline CPCCRN & $\begin{array}{l}\text { Collaborative Pediatric Critical Care Research } \\
\text { Network }\end{array}$ \\
\hline CPR & cardio-respiratory arrest \\
\hline HRQoL & health-related quality of life \\
\hline HUI & health utilities index \\
\hline MAHSC & multi-attribute health status classification \\
\hline MOF & multi-organ failure \\
\hline PELOD & paediatric logistic organ dysfunction \\
\hline PICU & paediatric intensive care unit \\
\hline PTSD & post-traumatic stress disorder \\
\hline RAHC & Royal Alexandra Hospital for Children \\
\hline QoL & quality of life \\
\hline
\end{tabular}

\section{Introduction}

The development of paediatric intensive care has contributed to improved survival rates in children with critical illnesses $[68,69]$. Consequently, new disease patterns have emerged due to long-term complications and effects of the original illness and its treatment. In addition to survival and morbidity, physical and psychological sequelae, as well as 
the quality of life $(\mathrm{QoL})$ in survivors and in their families are important outcome measures.

Historically, outcome research in paediatrics is either based on an age-specific approach, such as follow-up studies of premature infants $[41,72,73]$, or on a more disease-oriented approach, such as follow-up studies in survivors of cardiothoracic surgery or trauma $[15,55,64,70]$. These studies have shown substantial physical, psychological and neurocognitive sequelae, interfering with daily life and normal development. In addition, effects on parents and siblings have been shown [26]. Evaluative research of adult intensive care survivors showed the effect of intensive care treatment per se. Irrespective of the underlying illnesses, sequelae on all domains with effects on QoL were found [2, 19, 58, 75]. In multi-disciplinary paediatric intensive care unit (PICU) populations, reports on outcome are scarce [24, 25].

Based on these observations, we believe that follow-up research of paediatric intensive care survivors and their families is needed to evaluate: (1) physical sequelae and their impact during growth and development; (2) psychological sequelae in patients and their families and their impact on the QoL of patients and family members; and (3) the need for treatment and support after discharge.

The aim of this article is to provide an overview of the available literature concerning the different domains of QoL (i.e. physical, psychological and social functioning) in children surviving paediatric intensive care, including the effect on parents, and to suggest directions for future follow-up research.

\section{Methods}

To identify studies eligible for this review, we searched Medline (1966-2006), EMBASE (1974-2006), CINAHL (1982-2006), pre-CINAHL and the Cochrane Library (2006) in March 2006. In the search strategy, all terms mapped to the appropriate MeSH/EMTREE subject headings and "exploded" were used; among them were: paediatric intensive care unit (PICU), septic shock, respiratory insufficiency, meningococcal disease, central venous catheterisation, intubation, physical and psychological sequelae, post-traumatic stress disorder (PTSD), QoL, health status and long-term outcome.

\section{Definitions}

Functional health is defined as an individual's ability to perform normal daily activities, to fulfil usual roles and to maintain health and well-being.

QoL is defined as an individual's perception of their position in life, in the context of the culture and value systems and in relation to their goals, expectations, standards and concerns [1].

Health-related QoL (HRQoL) is defined as QoL in which a dimension of personal judgement over one's health and disease is added [21].

\section{Study selection}

Studies were selected for review if they met two inclusion criteria: (1) study of a representative population of PICU survivors (defined as a population consisting of medical and/or surgical PICU patients $<18$ years old) and (2) evaluation of physical sequelae, measurement of QoL or functional health $>30$ days after PICU discharge. Because of the limited number of studies, the measurement tools did not need to be standardised. Studies with a retrospective and prospective design were included.

Excluded were: (1) studies in homogeneous PICU populations (e.g. survivors of cardiothoracic surgery and trauma) reporting diagnosis-related outcome in particular but not intensive care treatment as such, and (2) studies evaluating mortality only.

\section{Results}

Eligible studies and quality of the studies

Twenty-seven studies were found in which one or more aspects of long-term sequelae in PICU survivors and/or their families were described. The patient characteristics, populations, measurement tools and outcomes are described in Tables 1 and 2. The quality criteria are described in Table 3. None of the studies met all of the quality criteria. In studies describing the same outcome aspect, differences in study population, follow-up time and measurement tools make the comparison and synthesis of results difficult.

Physical and neuro-cognitive sequelae (Table 1)

In 12 studies that included in total 340 patients, aspects of physical and neuro-cognitive sequelae were evaluated.

Neurological evaluation was conducted in five studies including 275 survivors. The majority of the children were neurologically normal. In the remaining children, disabilities such as hearing loss, coordination, cognition and developmental problems turned out to be severe [23, 35, 43, 53, 59].

Pulmonary evaluation was conducted in six studies including 65 patients [6, 14, 22, 30, 48, 74]. Restrictive and obstructive disease and hypoxaemia during exercise was found. 


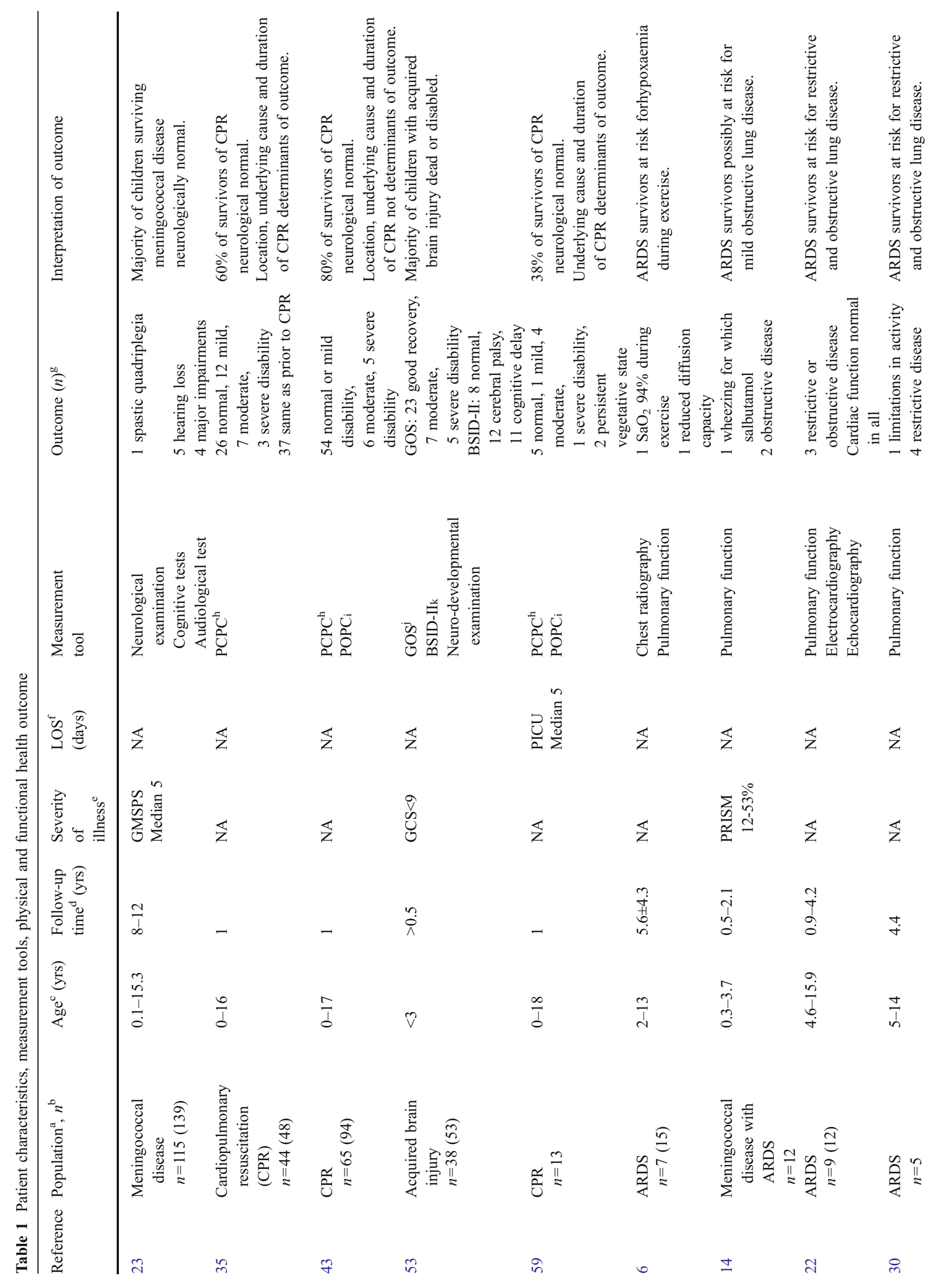




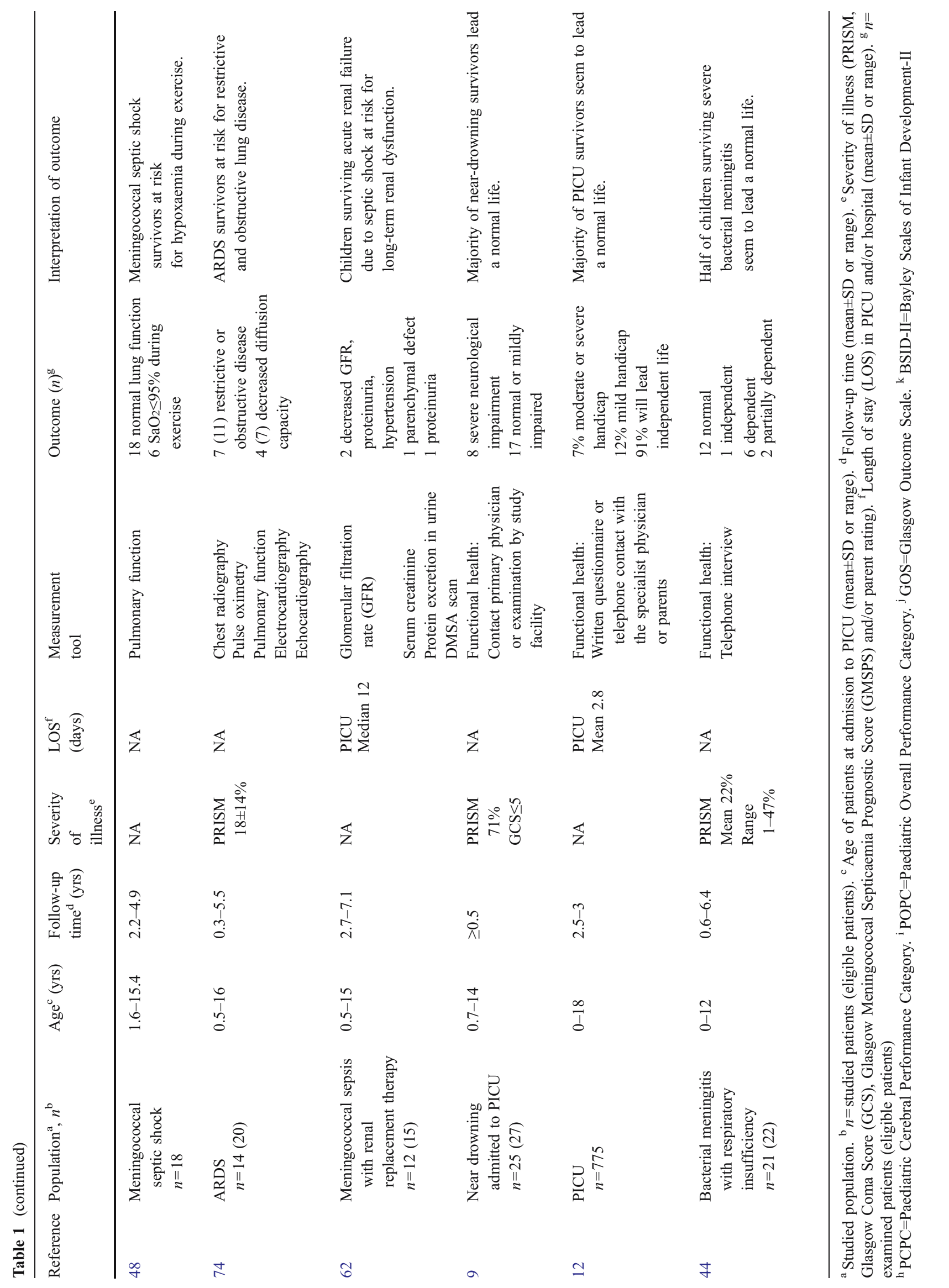




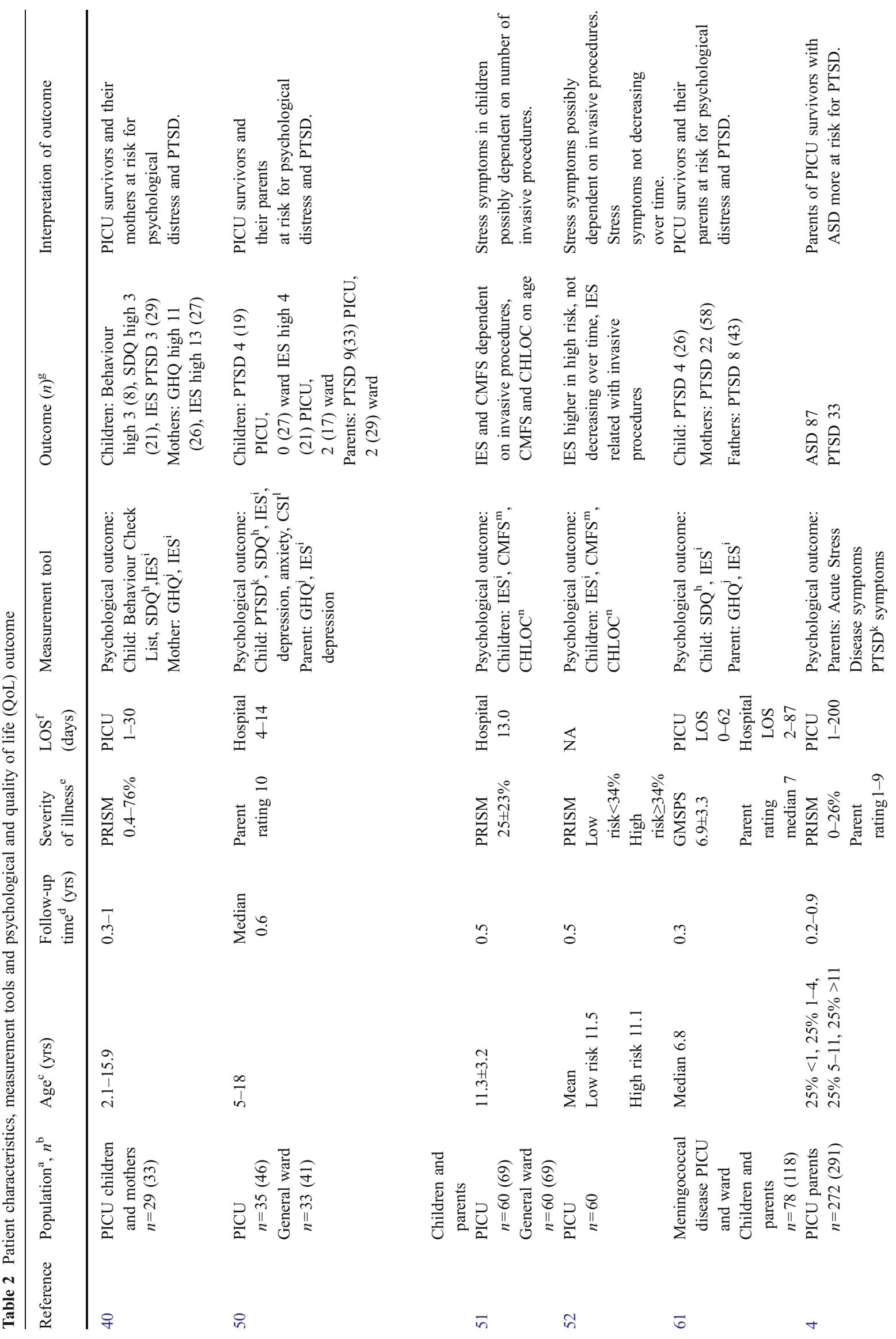




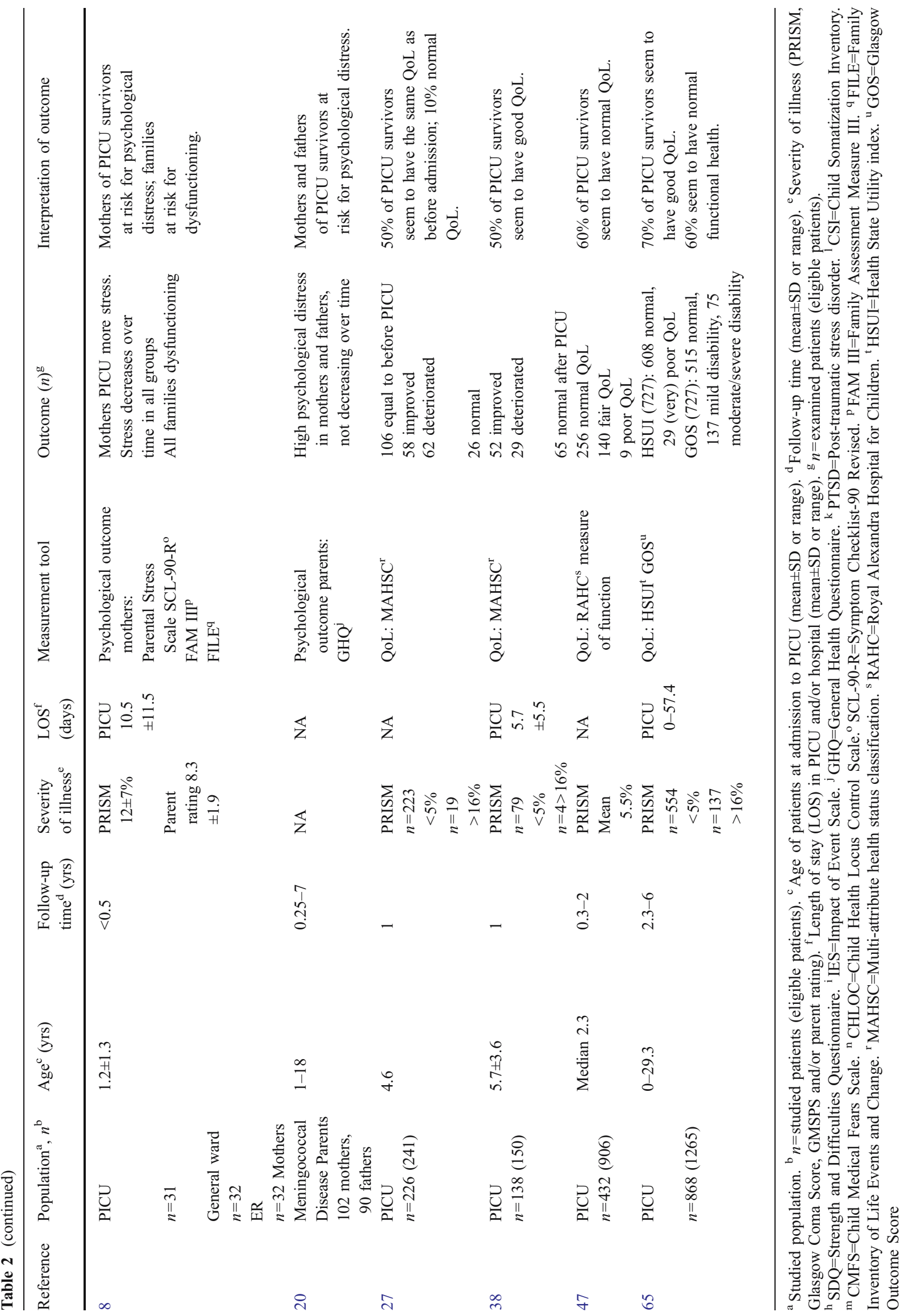


Table 3 Quality assessment of reviewed studies

\begin{tabular}{|c|c|c|c|c|c|}
\hline Reference & $\begin{array}{l}\text { Selection bias } \\
\text { excluded }^{\text {a }}\end{array}$ & $\begin{array}{l}\text { Selective loss to follow-up } \\
\text { excluded }^{\text {b }}\end{array}$ & $\begin{array}{l}\text { Exposure clearly } \\
\text { defined }^{\text {c }}\end{array}$ & $\begin{array}{l}\text { Outcome clearly } \\
\text { defined }^{\text {d }}\end{array}$ & $\begin{array}{l}\text { Control group } \\
\text { included }^{\mathrm{e}}\end{array}$ \\
\hline 4 & yes & yes & yes & yes & no \\
\hline 6 & no & no & yes & yes & no \\
\hline 8 & no & no & yes & yes & yes \\
\hline 9 & no & yes & yes & no & no \\
\hline 12 & yes & yes & yes & yes & no \\
\hline 14 & yes & yes & yes & yes & no \\
\hline 20 & yes & yes & yes & yes & no \\
\hline 22 & no & no & no & yes & no \\
\hline 23 & no & no & yes & yes & yes \\
\hline 27 & yes & no & yes & yes & no \\
\hline 30 & no & no & no & yes & no \\
\hline 35 & yes & no & yes & yes & no \\
\hline 38 & no & no & yes & yes & no \\
\hline 40 & no & yes & yes & yes & no \\
\hline 43 & no & no & yes & yes & no \\
\hline 44 & yes & yes & yes & yes & no \\
\hline 47 & yes & no & yes & yes & no \\
\hline 48 & no & no & yes & yes & no \\
\hline 50 & yes & no & yes & yes & yes \\
\hline 51 & no & yes & yes & yes & yes \\
\hline 52 & no & yes & yes & yes & yes \\
\hline 53 & yes & yes & yes & yes & no \\
\hline 59 & yes & no & yes & yes & no \\
\hline 61 & no & yes & yes & yes & no \\
\hline 62 & yes & no & yes & yes & no \\
\hline 65 & no & no & yes & yes & no \\
\hline 74 & yes & yes & yes & yes & no \\
\hline
\end{tabular}

${ }^{\mathrm{a}}$ Selection bias excluded (i.e. exclusion of $>10 \%$ of the studied population excluded). ${ }^{\mathrm{b}}$ Selective loss to follow-up excluded (i.e. description of patients lost to follow-up and comparison with those remaining in the study). ${ }^{\mathrm{c}}$ Exposure clearly defined (i.e. clear definition of the studied population).

${ }^{\mathrm{d}}$ Outcome clearly defined (i.e. clear definition of outcome measures). ${ }^{\mathrm{e}}$ Comparison with control group (i.e. children admitted to general ward)

Cardiac evaluation was conducted in two studies including 23 survivors [22, 74]. No abnormalities were found, except for left ventricular hypertrophy in one child.

Renal evaluation was conducted in one study including 12 survivors [62]. In two children, glomerular filtration was impaired, one had hypertension and one had proteinuria.

\section{Psychological sequelae (Table 2)}

Various questionnaires were used. Cut-off points for the diagnosis of PTSD differed between studies but all of them showed high scores for PTSD in children and parents.

Psychological evaluation of children was conducted in five studies including 202 children [40, 50-52, 61]. Symptoms of PTSD were found in 11 of 74 evaluated children. In one study, a relation was found between invasive procedures and high scores [52].

Psychological evaluation of parents was conducted in six studies including parents of 547 children [4, 8, 20, 40, 50, 61]. Symptoms of PTSD were found in 72 of 295 evaluated parents. In some studies, a relation was found between high scores and illness severity as perceived by parents $[4,50$, 61]. In one study, these high scores decreased over time [8].

Functional health and QoL (Tables 1 and 2)

Evaluation of functional health was conducted in three studies including 821 children [9, 12, 44]. The majority of the children seemed to have normal functional health; the remainder was found to be seriously impaired.

Evaluation of $Q o L$ was conducted in four studies including 1,664 children [27, 38, 47, 65]. QoL was evaluated using three different questionnaires. In the majority of children, the QoL was normal or equal to the QoL before PICU admission. In all studies, some of the children had poor QoL.

\section{Discussion}

Only 27 studies consisting of 3,444 PICU survivors met our inclusion criteria. The small numbers, heterogeneity of the 
studied populations and the used measurement tools, the frequent use of non-validated measurement tools and the various aspects of outcomes studied make aggregation of the data and, therefore, strong conclusive statements difficult.

Physical sequelae

The reviewed studies report distinct physical sequelae, including neurological abnormalities in PICU survivors. Standardised neurological examination of PICU survivors was validated in 1994 but very few studies have been carried out since $[24,25]$. As neurological problems have a great impact on daily life, standardised evaluation and adequate support and rehabilitation seem to be relevant, similar to in NICU survivors [11, 46, 56].

Follow-up studies evaluating lung function in children are hampered by the small incidence of severe respiratory insufficiency in children [49]. In adult respiratory distress syndrome (ARDS), the recovery of lung function is shown during the first year and physical limitations seem to be partly dependent on lung function $[34,58]$. In infants and children, post-natal lung growth may contribute to the improvement of lung function after critical illness. In addition to lung function, the long-term effect of small airway disease should be evaluated, for instance, in children with respiratory syncitial virus infection.

Data on the structured evaluation of cardiac and renal function in paediatric and adult ICU survivors is not available. In young children, septic shock and the need for vasoactive support of the circulation may interact with the developing myocardium and may have persistent effects on cardiac growth and function $[10,67,77]$.

Complications of intensive care procedures per se, (e.g. vascular complications due to intra-vascular catheters and side-effects of ototoxic drugs and sedatives) are not evaluated $[5,18,32,33,45,54,57,63]$. One can assume the exact incidence of physical sequelae to be higher than has been reported so far.

Psychological sequelae and functional health and QoL

In the reviewed studies, psychological sequelae have been established in $10-14 \%$ of survivors and their parents. The comparison of findings is hampered due to different measurement tools and cut-off points for the diagnosis of PTSD and various follow-up intervals. Risk factors accounting for hampered psychological outcome could be diverse (severity of illness, being removed from one's child, having been witness to the accident, mental health, family functioning, social support, coping strategies and lack of information from the medical team) [17, 26, 29, 31]. Psychological support to improve coping strategies and prevent over-protection might improve psychological out- come in children and parents $[3,28]$. Further research is essential to establish the appropriate time and extent of the psychological support needed.

Cognitive sequelae have rarely been studied in the reviewed studies. Adequate neuro-cognitive evaluation is both expensive and time-consuming. Studies in neonatal ICU survivors show substantial cognitive dysfunction with great impact on daily life [7]. Consequently, early intervention, education and rehabilitation are expected to improve daily life $[11,46]$.

A majority of PICU survivors seem to have unchanged functional health and good QoL. In the reviewed studies, functional health is evaluated by telephone interviews [27, $38,47,65]$. In most of these studies, the physician rather than the child or its parents evaluates functional health. Ideal (HR)QoL questionnaires should measure all aspects of QoL and preferably be filled in by the children themselves. Proxy investigation of functional health and (HR) QoL (in children $<6-8$ years of age) is second best $[36,37$, $39,66]$. Besides, the pre-morbid state is probably an important factor which is difficult to assess [16].

Suggestions for future follow-up research

The reviewed studies have a number of methodological limitations. Heterogeneity is the most important one. Consensus on all aspects of follow-up research is essential for well-founded conclusions. For example, structured and standardised evaluation of: (1) organ system function with a validated tool such as the Paediatric Logistic Organ Dysfunction (PELOD) score [13, 42, 60, 71]; (2) neurocognitive function; (3) complications of PICU treatment; and (4) (HR)QoL are warranted. Multi-centre studies as proposed by the Collaborative Pediatric Critical Care Research Network (CPCCRN) with a uniform approach will provide answers either in general PICU cohorts or in disease-oriented study groups [76].

In conclusion, this review indicates that PICU survivors and their parents may have substantial physical and psychological sequelae interacting with QoL. Because of longer life expectancy, longer follow-up time is warranted, emphasising the consequences for health care in children. We believe that paediatric intensivists and psychologists should be involved as core members of follow-up teams.

\section{References}

1. World Health Organization (WHO) (1979) The first ten years of the World Health Organization. WHO, Geneva, Switzerland

2. Angus DC, Carlet J (2003) Surviving intensive care: a report from the 2002 Brussels Roundtable. Intensive Care Med 29:368-377 
3. Anthony KK, Gil KM, Schanberg LE (2003) Brief report: parental perceptions of child vulnerability in children with chronic illness. J Pediatr Psychol 28:185-190

4. Balluffi A, Kassam-Adams N, Kazak A, Tucker M, Dominguez T, Helfaer M (2004) Traumatic stress in parents of children admitted to the pediatric intensive care unit. Pediatr Crit Care Med 5:547-553

5. Beck C, Dubois J, Grignon A, Lacroix J, David M (1998) Incidence and risk factors of catheter-related deep vein thrombosis in a pediatric intensive care unit: a prospective study. J Pediatr 133:237-241

6. Ben-Abraham R, Weinbroum AA, Roizin H, Efrati O, Augarten A, Harel R, Moreh O, Barzilay Z, Paret G (2002) Long-term assessment of pulmonary function tests in pediatric survivors of acute respiratory distress syndrome. Med Sci Monit 8:CR153CR157

7. Bhutta AT, Cleves MA, Casey PH, Cradock MM, Anand KJS (2002) Cognitive and behavioral outcomes of school-aged children who were born preterm: a meta-analysis. JAMA 288:728-737

8. Board R, Ryan-Wenger N (2002) Long-term effects of pediatric intensive care unit hospitalization on families with young children. Heart Lung 31:53-66

9. Bratton SL, Jardine DS, Morray JP (1994) Serial neurologic examinations after near drowning and outcome. Arch Pediatr Adolesc Med 148:167-170

10. Briassoulis G, Narlioglou M, Zavras N, Hatzis T (2001) Myocardial injury in meningococcus-induced purpura fulminans in children. Intensive Care Med 27:1073-1082

11. Brooks-Gunn J, McCarton CM, Casey PH, McCormick MC, Bauer CR, Bernbaum JC, Tyson J, Swanson M, Bennett FC, Scott DT (1994) Early intervention in low-birth-weight premature infants. Results through age 5 years from the Infant Health and Development Program. JAMA 272:1257-1262

12. Butt W, Shann F, Tibballs J, Williams J, Cuddihy L, Blewett L, Farley M (1990) Long-term outcome of children after intensive care. Crit Care Med 18:961-965

13. Curley MA, Zimmerman JJ (2005) Alternative outcome measures for pediatric clinical sepsis trials. Pediatr Crit Care Med 6:S150 S156

14. Dahlem P, de Jongh FHC, Griffioen RW, Bos AP, van Aalderen WMC (2004) Respiratory sequelae after acute hypoxemic respiratory failure in children with meningococcal septic shock. Crit Care Shock 7:20-26

15. Davey TM, Aitken LM, Kassulke D, Bellamy N, Ambrose J, Gee T, Clark M (2005) Long-term outcomes of seriously injured children: a study using the Child Health Questionnaire. J Paediatr Child Health 41:278-283

16. Demellweek C, Baldwin T, Appleton R, Al-Kharusi A (2002) A prospective study and review of pre-morbid characteristics in children with traumatic brain injury. Pediatr Rehabil 5:81-89

17. Diaz-Caneja A, Gledhill J, Weaver T, Nadel S, Garralda E (2005) A child's admission to hospital: a qualitative study examining the experiences of parents. Intensive Care Med 31:1248-1254

18. Dominguez KD, Crowley MR, Coleman DM, Katz RW, Wilkins DG, Kelly HW (2006) Withdrawal from lorazepam in critically ill children. Ann Pharmacother 40:1035-1039

19. Dowdy DW, Eid MP, Sedrakyan A, Mendez-Tellez PA, Pronovost PJ, Herridge MS, Needham DM (2005) Quality of life in adult survivors of critical illness: a systematic review of the literature. Intensive Care Med 31:611-620

20. Ehrlich TR, von Rosenstiel I, Grootenhuis MA, Gerrits AI, Bos AP (2005) Long-term psychological distress in parents of child survivors of severe meningococcal disease. Pediatr Rehabil 8:220-224

21. Eiser C, Morse R (2001) Quality-of-life measures in chronic diseases of childhood. Health Technol Assess 5:1-157
22. Fanconi S, Kraemer R, Weber J, Tschaeppeler H, Pfenninger J (1985) Long-term sequelae in children surviving adult respiratory distress syndrome. J Pediatr 106:218-222

23. Fellick JM, Sills JA, Marzouk O, Hart CA, Cooke RW, Thomson AP (2001) Neurodevelopmental outcome in meningococcal disease: a case-control study. Arch Dis Child 85:6-11

24. Fiser DH (1992) Assessing the outcome of pediatric intensive care. J Pediatr 121:68-74

25. Fiser DH (1994) Outcome evaluations as measures of quality in pediatric intensive care. Pediatr Clin North Am 41:1423-1438

26. Foster M, Chaboyer W (2003) Family carers of ICU survivors: a survey of the burden they experience. Scand J Caring Sci 17:205-214

27. Gemke RJBJ, Bonsel GJ, van Vught AJ (1995) Long-term survival and state of health after paediatric intensive care. Arch Dis Child 73:196-201

28. Gleason TR, Evans ME (2004) Perceived vulnerability: a comparison of parents and children. J Child Health Care 8:279287

29. Goldbeck L (2001) Parental coping with the diagnosis of childhood cancer: gender effects, dissimilarity within couples, and quality of life. Psychooncology 10:325-335

30. Golder NDB, Lane R, Tasker RC (1998) Timing of recovery of lung function after severe hypoxemic respiratory failure in children. Intensive Care Med 24:530-533

31. Grootenhuis MA, Last BF (1997) Adjustment and coping by parents of children with cancer: a review of the literature. Support Care Cancer 5:466-484

32. Gustafson LM, Hartley BE, Cotton RT (2001) Acquired total (grade 4) subglottic stenosis in children. Ann Otol Rhinol Laryngol 110:16-19

33. Halpern NA, Pastores SM, Price JB, Alicea M (1999) Hearing loss in critical care: an unappreciated phenomenon. Crit Care Med 27:211-219

34. Herridge MS, Cheung AM, Tansey CM, Matte-Martyn A, DiazGranados N, Al Saidi F, Cooper AB, Guest CB, Mazer CD, Mehta S, Stewart TE, Barr A, Cook D, Slutsky AS (2003) One-year outcomes in survivors of the acute respiratory distress syndrome. N Engl J Med 348:683-693

35. Horisberger T, Fischer E, Fanconi S (2002) One-year survival and neurological outcome after pediatric cardiopulmonary resuscitation. Intensive Care Med 28:365-368

36. Janse AJ, Gemke RJBJ, Uiterwaal CSPM, van der Tweel I, Kimpen JLL, Sinnema G (2004) Quality of life: patients and doctors don't always agree: a meta-analysis. J Clin Epidemiol 57:653-661

37. Janse AJ, Uiterwaal CSPM, Gemke RJBJ, Kimpen JLL, Sinnema G (2005) A difference in perception of quality of life in chronically ill children was found between parents and pediatricians. J Clin Epidemiol 58:495-502

38. Jayshree M, Singhi SC, Malhi P (2003) Follow up of survival and quality of life in children after intensive care. Indian Pediatr 40:303-309

39. Jokovic A, Locker D, Guyatt G (2004) How well do parents know their children? Implications for proxy reporting of child healthrelated quality of life. Qual Life Res 13:1297-1307

40. Judge D, Nadel S, Vergnaud S, Garralda ME (2002) Psychiatric adjustment following meningococcal disease treated on a PICU. Intensive Care Med 28:648-650

41. Klassen AF, Lee SK, Raina P, Chan HW, Matthew D, Brabyn D (2004) Health status and health-related quality of life in a population-based sample of neonatal intensive care unit graduates. Pediatrics 113:594-600

42. Leteurtre S, Martinot A, Duhamel A, Proulx F, Grandbastien B, Cotting J, Gottesman R, Joffe A, Pfenninger J, Hubert P, Lacroix J, Leclerc F (2003) Validation of the paediatric logistic organ dysfunction (PELOD) score: prospective, observational, multicentre study. Lancet 362:192-197 
43. Lopez-Herce J, Garcia C, Rodriguez-Nunez A, Dominguez P, Carrillo A, Calvo C, Delgado MA (2005) Long-term outcome of paediatric cardiorespiratory arrest in Spain. Resuscitation 64:79-85

44. Madagame ET, Havens PL, Bresnahan JM, Babel KL, Splaingard ML (1995) Survival and functional outcome of children requiring mechanical ventilation during therapy for acute bacterial meningitis. Crit Care Med 23:1279-1283

45. Male C, Chait P, Andrew M, Hanna K, Julian J, Mitchell L (2003) Central venous line-related thrombosis in children: association with central venous line location and insertion technique. Blood $101: 4273-4278$

46. McCormick MC, Brooks-Gunn J, Buka SL, Goldman J, Yu J, Salganik M, Scott DT, Bennett FC, Kay LL, Bernbaum JC, Bauer CR, Martin C, Woods ER, Martin A, Casey PH (2006) Early intervention in low birth weight premature infants: results at 18 years of age for the Infant Health and Development Program. Pediatrics 117:771-780

47. Morrison AL, Gillis J, O'Connell AJ, Schell DN, Dossetor DR, Mellis C (2002) Quality of life of survivors of pediatric intensive care. Pediatr Crit Care Med 3:1-5

48. Plötz FB, van Vught H, Uiterwaal CSPM, Riedijk M, van der Ent CK (2001) Exercise-induced oxygen desaturation as a late complication of meningococcal septic shock syndrome. JAMA 285:293-294

49. Randolph AG, Wypij D, Venkataraman ST, Hanson JH, Gedeit RG, Meert KL, Luckett PM, Forbes P, Lilley M, Thompson J, Cheifetz IM, Hibberd P, Wetzel R, Cox PN, Arnold JH (2002) Effect of mechanical ventilator weaning protocols on respiratory outcomes in infants and children: a randomized controlled trial. JAMA 288:2561-2568

50. Rees G, Gledhill J, Garralda ME, Nadel S (2004) Psychiatric outcome following paediatric intensive care unit (PICU) admission: a cohort study. Intensive Care Med 30:1607-1614

51. Rennick JE, Johnston CC, Dougherty G, Platt R, Ritchie JA (2002) Children's psychological responses after critical illness and exposure to invasive technology. J Dev Behav Pediatr 23:133-144

52. Rennick JE, Morin I, Kim D, Johnston CC, Dougherty G, Platt R (2004) Identifying children at high risk for psychological sequelae after pediatric intensive care unit hospitalization. Pediatr Crit Care Med 5:358-363

53. Robertson CM, Joffe AR, Moore AJ, Watt JM (2002) Neurodevelopmental outcome of young pediatric intensive care survivors of serious brain injury. Pediatr Crit Care Med 3:345-350

54. Robertson CMT, Juzer MT, Peliowski A, Philip CE, Cheung P-Y (2006) Ototoxic drugs and sensorineural hearing loss following severe neonatal respiratory failure. Acta Paediatr 95:214-223

55. Rose M, Köhler K, Kohler F, Sawitzky B, Fliege H, Klapp BF (2005) Determinants of the quality of life of patients with congenital heart disease. Qual Life Res 14:35-43

56. Savage RC, Pearson S, McDonald H, Potoczny-Gray A, Marchese N (2001) After hospital: working with schools and families to support the long term needs of children with brain injuries. Neurorehabilitation 16:49-58

57. Schelling G, Kilger E, Roozendaal B, de Quervain DJ, Briegel J, Dagge A, Rothenhausler HB, Krauseneck T, Nollert G, Kapfhammer HP (2004) Stress doses of hydrocortisone, traumatic memories, and symptoms of posttraumatic stress disorder in patients after cardiac surgery: a randomized study. Biol Psychiatry 55:627-633

58. Schelling G, Stoll C, Vogelmeier C, Hummel T, Behr J, Kapfhammer HP, Rothenhausler HB, Haller M, Durst K, Krauseneck T, Briegel J (2000) Pulmonary function and healthrelated quality of life in a sample of long-term survivors of the acute respiratory distress syndrome. Intensive Care Med 26:1304-1311
59. Schindler MB, Bohn D, Cox PN, McCrindle BW, Jarvis A, Edmonds J, Barker G (1996) Outcome of out-of-hospital cardiac or respiratory arrest in children. N Engl J Med 335(20):14731479

60. Schoenfeld DA, Bernard GR; ARDS Network (2002) Statistical evaluation of ventilator-free days as an efficacy measure in clinical trials of treatments for acute respiratory distress syndrome. Crit Care Med 30:1772-1777

61. Shears D, Nadel S, Gledhill J, Garralda ME (2005) Short-term psychiatric adjustment of children and their parents following meningococcal disease. Pediatr Crit Care Med 6:39-43

62. Slack R, Hawkins KC, Gilhooley L, Addison GM, Lewis MA, Webb NJ (2005) Long-term outcome of meningococcal sepsisassociated acute renal failure. Pediatr Crit Care Med 6:477-479

63. Sorce LR (2005) Adverse responses: sedation, analgesia and neuromuscular blocking agents in critically ill children. Crit Care Nurs Clin North Am 17:441-450

64. Sturms LM, van der Sluis CK, Stewart RE, Groothoff JW, ten Duis HJ, Eisma WH (2005) A prospective study on paediatric traffic injuries: health-related quality of life and post-traumatic stress. Clin Rehabil 19:312-322

65. Taylor A, Butt W, Ciardulli M (2003) The functional outcome and quality of life of children after admission to an intensive care unit. Intensive Care Med 29:795-800

66. Theunissen NC, Vogels TG, Koopman HM, Verrips GH, Zwinderman KA, Verloove-Vanhorick SP, Wit JM (1998) The proxy problem: child report versus parent report in health-related quality of life research. Qual Life Res 7:387-397

67. Thiru Y, Pathan N, Bignall S, Habibi P, Levin M (2000) A myocardial cytotoxic process is involved in the cardiac dysfunction of meningococcal septic shock. Crit Care Med 28:2979-2983

68. Thorburn K, Baines P, Thomson A, Hart CA (2001) Mortality in severe meningococcal disease. Arch Dis Child 85:382-385

69. Tilford JM, Roberson PK, Lensing S, Fiser DH (1998) Differences in pediatric ICU mortality risk over time. Crit Care Med 26:1737-1743

70. van Rijen EH, Utens EM, Roos-Hesselink JW, Meijboom FJ, van Domburg RT, Roelandt JR, Bogers AJ, Verhulst FC (2003) Psychosocial functioning of the adult with congenital heart disease: a 20-33 years follow-up. Eur Heart J 24:673-683

71. Vincent JL (2004) Endpoints in sepsis trials: more than just 28day mortality? Crit Care Med 32:S209-S213

72. Vohr BR, O'Shea M, Wright LL (2003) Longitudinal multicenter follow-up of high-risk infants: why, who, when, and what to assess. Semin Perinatol 27:333-342

73. Walther FJ, den Ouden AL, Verloove-Vanhorick SP (2000) Looking back in time: outcome of a national cohort of very preterm infants born in The Netherlands in 1983. Early Hum Dev 59:175-191

74. Weiss I, Ushay HM, DeBruin W, O’Loughlin J, Rosner I, Notterman D (1996) Respiratory and cardiac function in children after acute hypoxemic respiratory failure. Crit Care Med 24:148-154

75. Williams TA, Dobb GJ, Finn JC, Webb SA (2005) Long-term survival from intensive care: a review. Intensive Care Med 31:1306-1315

76. Willson DF, Dean JM, Newth C, Pollack M, Anand KJ, Meert K, Carcillo J, Zimmerman J, Nicholson C (2006) Collaborative Pediatric Critical Care Research Network (CPCCRN). Pediatr Crit Care Med 7:301-307

77. Zhang H, Cotecchia S, Thomas SA, Tanoue A, Tsujimoto G, Faber JE (2004) Gene deletion of dopamine $\beta$-hydroxylase and $\alpha 1$-adrenoceptors demonstrates involvement of catecholamines in vascular remodeling. Am J Physiol Heart Circ Physiol 287: H2106-H2114 